\title{
Intravenous Pamidronate in Osteogenesis Imperfecta Type VII
}

\author{
Moira S. Cheung • Francis H. Glorieux • \\ Frank Rauch
}

Received: 10 August 2008/ Accepted: 11 December 2008

(C) Springer Science+Business Media, LLC 2009

\begin{abstract}
Cyclical intravenous treatment with pamidronate is widely used to treat osteogenesis imperfecta (OI) types I, III, and IV, which are due to dominant mutations affecting collagen type I alpha chains. There is no information about the effects of pamidronate in children with OI type VII, an autosomal-recessive form of OI caused by a mutation in the cartilage-associated protein gene. In this retrospective single-center study, we compared the effects of pamidronate in four girls with OI type VII (age range 3.9-12.7 years) to those in eight girls with OI types caused by collagen type I mutations who were matched for age and disease severity. During 3 years of pamidronate therapy, lumbar spine areal bone mineral density increased and lumbar vertebral bodies improved in shape in patients with OI type VII. Other outcomes such as fracture rates and mobility scores did not show statistically significant changes in this small study cohort. There were no significant side effects noted during the time of follow-up. Thus, intravenous treatment with pamidronate seems to be safe and of some benefit in patients with OI type VII.
\end{abstract}

Keywords Cartilage associated protein - Children . Fractures · Osteogenesis imperfecta $\cdot$ Pamidronate

\footnotetext{
M. S. Cheung · F. H. Glorieux · F. Rauch ( $\square)$

Genetics Unit, Shriners Hospital for Children and McGill

University, 1529 Cedar Avenue, Montreal, Quebec H3G 1A6,

Canada

e-mail: frauch@shriners.mcgill.ca

M. S. Cheung

e-mail: mcheung@shriners.mcgill.ca

F. H. Glorieux

e-mail: glorieux@shriners.mcgill.ca
}

Osteogenesis imperfecta (OI) type VII is characterized by bone fragility, long-bone deformities, shortness of proximal limb segments, and coxa vara [1]. In contrast to the classical forms of OI, patients with OI type VII do not have blue sclerae or dentinogenesis imperfecta [1]. Although the more common types of OI (I to IV) are usually inherited in an autosomal-dominant fashion and are due to mutations directly affecting collagen type I alpha chains, OI type VII is an autosomal-recessive disorder and is caused by mutations in the gene coding for cartilage-associated protein (CRTAP) [2]. CRTAP acts as a cofactor for the posttranslational modification of collagen type I. In the patients who were described in the original description of OI type VII, the disease was due to an intronic mutation in the CRTAP gene [1,2]. As a consequence of this mutation, CRTAP expression was decreased by $90 \%$ and the posttranslational modification of collagen type I was disturbed [2]. It was subsequently found that the manifestations in these patients apparently represent the milder end of the disease severity spectrum caused by CRTAP mutations. Complete absence of CRTAP expression leads to perinatal OI resulting in death or to very severe OI $[2,3]$.

In growing patients with moderate to severe OI types I to IV, the benefits of intravenous pamidronate treatment are amply documented [4]. Pamidronate therapy is associated with an increase in lumbar spine bone mineral density (BMD) and cortical thickness, improvement in vertebral shape, stronger muscles, and better mobility function. It is not known whether the benefits of pamidronate are similar in patients with the pathogenetically different OI type VII. In the present study, we therefore assessed the effects of pamidronate treatment in children and adolescents with OI type VII. The results were compared with those of patients who had OI caused by collagen type I mutations and who had a similar severity of the disease. 


\section{Patients and Methods}

\section{Patients}

The study group comprised all children and adolescents with OI type VII who received cyclical intravenous pamidronate treatment at the Shriners Hospital for Children in Montreal, Canada. The diagnosis of OI type VII was made on the basis of clinical, radiological, and histological features of the disease and confirmed by mutation analysis of the CRTAP gene.

Patients were eligible for pamidronate treatment if they had long-bone deformities or had experienced at least two fractures per year (including vertebral fractures). All four children (all girls) who were diagnosed with OI VII fulfilled these criteria for pamidronate treatment. At the time of analysis, each patient had completed 3 years of treatment.

Results in OI type VII patients were compared with those in a comparison group of eight OI patients who had mutations in either of the two genes that code for collagen type I alpha chains, COL1A1 or COL1A2. Two patients from the comparison group were matched for each patient with OI type VII on the basis of, in order of matching: sex; age; and criteria reflecting disease severity (lumbar spine areal BMD z-score and height $\mathrm{z}$-score) at the start of pamidronate therapy. Five of the patients in the OI comparison group were classified as having OI type I, two patients OI type IV, and one patient OI type III.

\section{Treatment}

Pamidronate was administered in cycles that lasted 3 days. On each day, a dose corresponding to $1 \mathrm{mg} / \mathrm{kg}$ body weight was given. The interval between cycles was 4 months in all patients. The yearly dose of pamidronate thus was $9 \mathrm{mg} / \mathrm{kg}$ [4]. Calcium and vitamin D intake were maintained as adequate according to the recommended daily allowance in all patients. All patients underwent standard physiotherapy, occupational therapy programs, and orthopedic care as required.

\section{Biochemical Measurements}

Serum total calcium, phosphate, and alkaline phosphatase activity were measured by standard methods (Monarch; Instrumentation Laboratories Inc., Lexington, MA). Serum parathyroid hormone concentration (fragment 39-84) was determined by radioimmunoassay [5]. 25-OH vitamin $\mathrm{D}$ and $1,25-\mathrm{OH}_{2}$ vitamin $\mathrm{D}$ were measured with radioimmunoassays (25-hydroxyvitamin D and 1,25-dihydroxyvitamin D Osteo SP; Incstar Corp., Stillwater, MN). Urinary creatinine concentration was quantified colorimetrically.
The bone resorption marker urinary cross-linked N-telopeptide of type I collagen (NTX) was quantified by enzyme-linked immunoabsorbent assay (Osteomark; Ostex, Seattle, WA) on the second void sample of the morning. Results for urinary NTX/creatinine ratios were compared with published reference data [6]. Patients were fasting at the time of blood and urine sampling.

\section{Radiological Analyses}

Vertebral morphometry was performed on lumbar vertebra L1 to L4 by means of standard lateral spine radiographs as previously described that were obtained at baseline and after 2 to 4 years of treatment [7]. Six landmarks were identified at the silhouette of each vertebral body, corresponding to the four corners of the vertebral body and the midpoints of the endplates. The point-to-point distances were measured with a dial reading caliper (General Tools, New York, NY) with a precision of $0.1 \mathrm{~mm}$. From these points, anterior, posterior, midheight, and lower length were measured. All vertical heights were expressed relative to lower vertebral length (vertebral height ratio) as described elsewhere [8]. Standard radiographs of the left hand and wrist were obtained before treatment to establish the presence of any radiological features of rickets.

Dual-energy X-ray absorptiometry was performed in the anterior-posterior direction at the lumbar spine (L1-L4) with a Hologic QDR $2000 \mathrm{~W}$ or 4500 device (Hologic Inc., Waltham, MA). Areal BMD results were transformed to agespecific z-scores combining reference data from Salle et al. and data provided by the densitometer manufacturer [9].

\section{Clinical Evaluation}

All OI patients were seen several times per year when they received pamidronate treatment. Clinical examination and biochemical measurements were performed at each visit and bone densitometry was performed at least once per year. Information about fractures was retrieved from medical charts. Only fractures confirmed on radiographs were counted. The annualized fracture incidence was determined separately for the 2 years before the start of pamidronate treatment and the first 3 years thereafter.

Height was measured with a Harpenden stadiometer (Holtain, Crymych, UK). Weight was determined by mechanical scales (Healthometer, Bridgeview, IL). Height and weight measurements were converted to age- and sexspecific z-scores on the basis of reference data published by the Centers for Disease Control and Prevention [10].

Grip force of the nondominant hand was determined with a standard adjustable-handle Jamar dynamometer (Preston, Jackson, MI) in patients who were older than 4 years. The maximal value of three trials was noted. Grip 
force results were transformed to age- and sex-specific zscores by using reference data from Rauch et al. [11].

The level of ambulation was scored for each child by physiotherapists experienced in the care of children with bone diseases according to the modified criteria of Bleck using a four-point scale as follows: nonwalker, score $=1$; therapeutic walker with or without the use of crutches, canes, or walker, score $=2$; household walker with or without the use of crutches, canes, or walker, score $=3$; neighborhood or community walker with or without the use of crutches, canes, or walker, score $=4$ [12].

Occupational therapists assessed patients before the start of pamidronate therapy and at each subsequent treatment cycle. The Pediatric Evaluation of Disability Inventory (PEDI) was used to evaluate gross motor abilities [13]. The PEDI includes 59 mobility items, which were reviewed with questionnaire and observations in each subject. Results are presented as scaled scores. Scaled scores are not adjusted for age and therefore can be used to describe the functional status of children at all ages to document individual improvements over time.

\section{Histomorphometry}

Transiliac bone biopsy specimens were obtained at baseline and after 2 to 4 years of pamidronate treatment. Whenever possible, labeling was performed before biopsy with demeclocycline ( 15 to $20 \mathrm{mg}$ per $\mathrm{kg}$ body weight per day taken orally for two 2-day periods separated by a 10-day free interval). Transiliac bone samples were collected 4 to 5 days after the labeling with a 5-mm Bordier trephine from a site located $2 \mathrm{~cm}$ below and behind the anterior superior iliac spine. Paired biopsy samples were available for histomorphometric analysis in three patients with OI type VII and five of the patients in the OI comparison group. Biopsy preparation and histomorphometric analyses were performed as previously described [14]. Results for histomorphometric parameters were expressed as a percentage of the average results in subjects without metabolic bone disorders [14]. Nomenclature and abbreviations follow the recommendations of the American Society for Bone and Mineral Research [15].

\section{Statistical Analyses}

Differences between the OI type VII and the OI comparison group were tested for significance by unpaired $t$-test or Mann-Whitney $U$-test, as appropriate. Analysis of variance, unpaired $t$-test, or Wilcoxon test were used to analyze changes during treatment. The $\chi^{2}$ test was used to evaluate differences in frequency of clinical signs between the groups. All tests were two-tailed, and throughout the study, $P<0.05$ was considered significant.

\section{Results}

Baseline height and lumbar spine areal BMD z-scores were low in the OI type VII group and by design similar to the OI comparison group (Table 1). A similar proportion of

Table 1 Comparison of baseline characteristics between patients with osteogenesis imperfecta (OI) type VII and a comparison group of patients with OI types I, III, and IV matched for sex (all female), age, and disease severity (based on lumbar spine areal bone mineral density [BMD] zscores and height) ${ }^{\mathrm{a}}$

\begin{tabular}{llll}
\hline Characteristic & OI type VII $(n=4)$ & OI comparison group $(n=8)$ & $P$ \\
\hline Age (years) & $6.9(3.9$ to 12.7$)$ & $6.6(2.2$ to 13.8$)$ & 0.98 \\
Height (z-score) & $-2.3(-3.7$ to -1.4$)$ & $-1.7(-10.6$ to -0.6$)$ & $-0.0(-4.0$ to 0.7$)$ \\
Weight (z-score) & $-0.2(-0.4$ to 1.0$)$ & $-3.9(-5.3$ to -3.1$)$ & 0.31 \\
Areal BMD (z-score) & $-3.0(-5.5$ to -2.9$)$ & $270(93)$ & $106(42)$ \\
Serum alkaline phosphatase (U/l) & $264(68)$ & & 0.28 \\
Urinary NTX/creatinine (\% of age and & $153(39)$ & 4 & 0.91 \\
$\quad$ sex-specific reference mean) & 3 & 2 & 0.09 \\
Long bone deformities (n) & 1 & 7 & 0.58 \\
Scoliosis (n) & 4 & 3 & 0.02 \\
Coxa Vara (n) & 2 & 6 & 0.49 \\
Vertebral compressions (n) & 0 & 0 & 0.06 \\
Dentinogenesis imperfecta (n) & 1 & & \\
Blue Sclerae (n) & & & 0.09 \\
Wormian bones (n) & & & \\
\hline
\end{tabular}

NTX N-telopeptide of type I collagen

${ }^{a}$ Values are given as median (range), mean (SD) or absolute numbers. $P$ values represent the significance of difference between the two groups (unpaired $t$-test, Mann-Whitney $U$-test or $\chi^{2}$ test, as appropriate) 
patients with OI type VII had long-bone deformities, scoliosis, and vertebral compressions when compared with the comparison group. Coxa vara was present in all patients with OI type VII and in one patient from the OI comparison group. None of the patients with OI type VII had either blue sclerae or dentinogenesis imperfecta. The mean (standard deviation) time of treatment with pamidronate was $2.9(0.2)$ years for patients with OI type VII and 3.0 (0.1) years for the controls $(P=0.4)$.

\section{Bone and Mineral Metabolism}

Baseline serum levels of total calcium, phosphorus, creatinine, and parathyroid hormone were within the reference ranges in all patients and were similar between the OI type VII and the OI comparison groups. Two of the patients with OI type VII and three patients of the OI comparison group had serum 25-OH vitamin D levels below $30 \mathrm{nmol} / \mathrm{l}$ at baseline. These patients subsequently received supplementation with vitamin $\mathrm{D}$ and calcium and achieved serum 25-OH vitamin D concentrations above $30 \mathrm{nmol} / \mathrm{l}$.

During the first 3 days of treatment, the mean (SE) total serum calcium concentration dropped by $0.22(0.15) \mathrm{mmol} /$ 1 to reach a nadir of $2.10 \mathrm{mmol} / \mathrm{l}$ (reference range 2.25 $2.63 \mathrm{mmol} / \mathrm{l}$ ) in patients with OI type VII. The OI comparison group had a similar drop in total serum calcium (a mean [SE] decrease of 0.26 [0.08] mmol/l; nadir $2.10 \mathrm{mmol} / \mathrm{l})$. In all patients, total serum calcium levels had returned to the reference range 4 months later, when the second infusion cycle was started.

As expected, fluctuations of serum calcium concentrations in OI type VII patients were associated with a counterregulatory mild increase in mean parathyroid hormone levels (mean [SE] increase of 2.4 [1.9] pmol/l; peak $10.3 \mathrm{pmol} / \mathrm{l}$; reference range $2.6-10 \mathrm{pmol} / \mathrm{l})$, a decrease in mean serum phosphorus levels (mean [SE] decrease of 0.44 [0.14] $\mathrm{mmol} / \mathrm{l}$ ) and an increase in $1,25-\mathrm{OH}_{2}$ vitamin $\mathrm{D}$ (mean [SE] increase of 49.7 [9.2] pmol/l) during the first infusion cycle. In all patients, parathyroid hormone levels had returned to the reference range by the start of the next infusion. Similar changes were observed in the OI comparison group (data not shown).

The long-term effects of pamidronate on biochemical results were evaluated in samples taken before each pamidronate infusion during the first 3 years of treatment. During this period, there was no significant change in serum levels of total calcium, phosphate, parathyroid hormone, $1,25-\mathrm{OH}_{2}$ vitamin $\mathrm{D}, 25-\mathrm{OH}$ vitamin $\mathrm{D}$, or alkaline phosphatase. However, urinary NTX significantly decreased during the first year and remained low over the subsequent 2 years. Similar results were found in the OI comparison group (data not shown).
OI TYPE VII

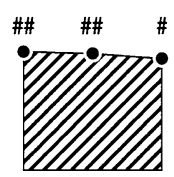

$\mathrm{PH} \mathrm{MH} \quad \mathrm{AH}$

AT START OF PAMIDRONATE

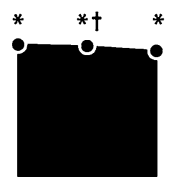

$\mathrm{PH} \quad \mathrm{MH} \quad \mathrm{AH}$

2-4 YEARS OF PAMIDRONATE
OI COMPARISON

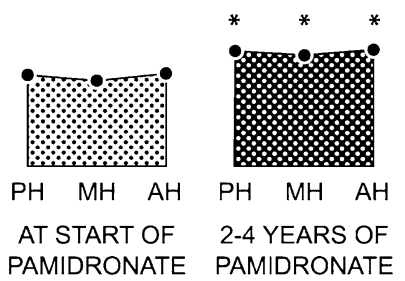

Fig. 1 Average vertebral body shape of L1 to L4 in patients with OI type VII and OI comparison patients before and after 2 to 4 years of pamidronate therapy. The heights of each vertebral body are normalized to the lower length of the vertebral body on the lateral lumbar spine radiograph. Significant differences $(P<0.05)$ between the comparison group and OI type VII patients are indicated by \# (pretreatment results) and $\dagger$ (results during treatment). Significant treatment changes within groups are marked by asterisks

\section{Radiology}

Lumbar spine areal BMD significantly increased in all patients during the 3-year treatment period. The mean (SD) increase in $\mathrm{z}$-score per year of treatment was 0.53 $(0.27)$ in patients with OI type VII and $0.86(0.35)$ for controls $(P=0.1$ for comparison of increase between the groups).

Vertebral morphometry at baseline showed that lumbar vertebral bodies L1 to L4 were significantly more compressed in the OI comparison group than in OI type VII patients (Fig. 1). The average anterior, posterior, and midheight of vertebral bodies L1 to L4 relative to the length of the vertebral body increased after at least 2 years of treatment in patients with OI type VII $(12 \%, 9 \%$, and $9 \%$ increase in height, respectively). OI comparison group also had increases in average anterior, posterior, and midheight lumbar vertebral body measurements $(27 \%, 31 \%$, and $35 \%$ increase in height, respectively).

\section{Iliac Bone Histomorphometry}

Qualitative assessment showed that trabeculae in OI type VII consisted of lamellar bone, both before and during pamidronate treatment. Quantitative analysis at baseline revealed that patients with OI type VII had a higher trabecular bone volume per tissue volume than patients in the OI comparison group (mean [SD] in OI type VII, $71 \%$ [11\%]; in the OI comparison group, 37\% [29\%], $P=0.048$; results expressed as a percentage of the mean of the age-specific reference range). However, treatmentassociated changes in bone volume per tissue volume were similar between groups (Fig. 2). Histomorphometric parameters of bone turnover activity, such as osteoid surface per bone surface and bone formation rate, showed the expected decline after treatment with pamidronate (Fig. 2). 

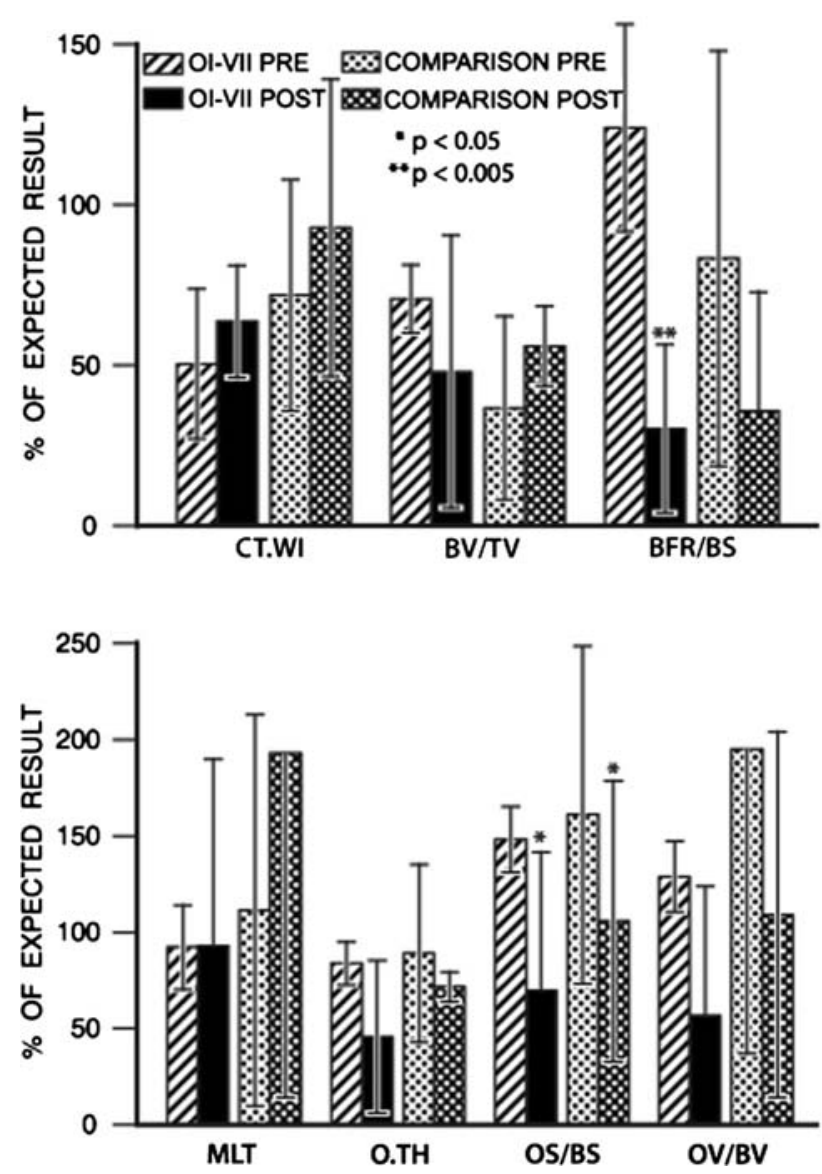

Fig. 2 Results of iliac bone histomorphometry in OI type VII (OIVII) patients and in the OI comparison group before (pre) and after (post) 3 years of pamidronate treatment. All results are expressed as a percentage of the age-specific average in subjects without metabolic bone disease (percentage of expected result). Ct.Wi, cortical width; $\mathrm{BV} / \mathrm{TV}$, bone volume per tissue volume; BFR/BS, bone formation rate per bone surface; Mlt, mineralization lag time; O.Th, osteoid thickness; OS/BS, osteoid surface per bone surface; OV/BV, osteoid volume per bone volume. Significant differences in results before and after the treatment period are indicated by asterisks: $* P<0.05$, $* * P<0.005$
Clinical Response

At baseline, the mean height $\mathrm{z}$-score was similarly low in the OI type VII and the OI comparison group (Table 1). Over the 3-year treatment period, height z-scores did not change significantly, showing that the growth rate was similar to healthy controls during this period.

Regardless of OI type, most patients had a mild reaction with pyrexia and generalized malaise during their first infusion. This reaction did not occur with subsequent infusions. No major side effects were observed during the 3 years of treatment.

There was no significant change in the fracture rates and mobility scores between baseline and after 3 years of treatment (Table 2). In patients with OI type VII, maximal isometric grip force was within the reference range at baseline and remained there during the 3 years of treatment ( $n=3$, z-score, mean [SD], 0.3 [1.3] with change in $\mathrm{z}$ score -0.1 [1.2]) and similarly in the comparison group ( $n=8$, z-score, mean [SD], 0.5 [0.7]). PEDI scores showed an upward trend in both the patients with OI type VII ( $n=4$, baseline mean [SD], 70 [27] with an increase over 3 years of 12.1 [4.1]) and the comparison group ( $n=7$, baseline mean [SD], 75 [22] with an increase over 3 years of 16 [6]) over the 3 years of treatment, although this did not reach statistical significance.

\section{Discussion}

This study suggests that cyclical intravenous pamidronate treatment increases lumbar spine areal BMD and also helps to reshape compressed vertebral bodies in growing patients with OI type VII. The treatment results in OI type VII patients with CRTAP mutations were broadly similar to those of a comparison group of OI patients who had collagen

Table 2 Clinical response to pamidronate treatment

\begin{tabular}{llllll}
\hline Patient & $\begin{array}{l}\text { Age at start of } \\
\text { treatment (years) }\end{array}$ & $\begin{array}{l}\text { Fracture incidence } \\
\text { before treatment } \\
\text { (/year) }\end{array}$ & $\begin{array}{l}\text { Fracture incidence } \\
\text { during 3 years of } \\
\text { treatment (/year) }\end{array}$ & $\begin{array}{l}\text { Ambulation score } \\
\text { at start of } \\
\text { treatment }\end{array}$ & $\begin{array}{l}\text { Ambulation score } \\
\text { after 3 years of } \\
\text { treatment }\end{array}$ \\
\hline 1 & 3.9 & 1.5 & 0.3 & 4 & 4 \\
2 & 5.3 & 0 & 0.7 & 1 & 2 \\
3 & 8.5 & 0.5 & 0 & 4 & 4 \\
4 & 12.7 & 0.5 & $0.50(0.44)$ & $3.25(1.50)$ & $3.50(1.00)$ \\
Mean (SD) & $7.6(3.9)$ & $0.63(0.63)$ & & & $3.50(1.07)$ \\
OI comparison group & & $0.63(0.44)$ & $0.50(0.54)$ & $3.75(0.71)$ \\
Mean (SD) & $7.5(3.8)$ & &
\end{tabular}

OI osteogenesis imperfecta 
type I mutations and who were matched for clinical indicators of disease severity. It thus seems that the effects of pamidronate effects in OI do not depend on mutation status.

The short-term safety profile of pamidronate in these patients seemed to be good, similar to what we had observed with the same treatment protocol in other OI types [16-19]. OI type VII patients also experienced a decrease in bone formation rate as was observed in other patient groups [17-20]. The long-term implications in terms of safety of this characteristic effect of pamidronate are still of concern.

The question of whether pamidronate treatment influences fracture rates in OI type VII patients can certainly not be answered in a report on four patients. The pretreatment fracture rate in the OI type VII cohort was less than a quarter of the one reported for a more severely affected group of OI patients in whom pamidronate seemed to have a large effect on fracture incidence [16]. Thus, a large study population would be necessary to evaluate the effect of bisphosphonate treatment on fracture rate in OI type VII. Similar considerations apply to other clinical responses.

The results of this report are obviously limited by the small study population and the observational study design. However, the known population of patients with CRTAP mutations is very small at present. Apart from the four patients included in this report, four of their adult relatives are the only other individuals with homozygous CRTAP mutations that have been reported to survive beyond early infancy [1-3]. Further treatment studies in OI type VII therefore require the identification of more patients with this disorder. The range of disease severity associated with such mutations has not yet been established and the incidence of OI type VII is not known. It is certainly conceivable that CRTAP mutation screening of OI patients who are negative for collagen type I mutations will identify more OI type VII patients in the future.

In conclusion, 3 years of intravenous pamidronate treatment in growing OI type VII patients was associated with an increase in areal BMD and some reshaping of compressed vertebral bodies. There were no significant side effects noted during the time of follow-up. Future treatment studies in OI type VII will require the identification of more patients with this disorder.

Acknowledgments We thank Mark Lepik for the preparation of the figures. This study was supported by the Shriners of North America. F.R. is a Chercheur-Boursier Clinicien of the Fonds de la Recherche en Santé du Québec.

\section{References}

1. Ward LM, Rauch F, Travers R, Chabot G, Azouz EM, Lalic L, Roughley PJ, Glorieux FH (2002) Osteogenesis imperfecta type
VII: an autosomal recessive form of brittle bone disease. Bone 31:12-18

2. Morello R, Bertin TK, Chen Y, Hicks J, Tonachini L, Monticone M, Castagnola P, Rauch F, Glorieux FH, Vranka J, Bachinger HP, Pace JM, Schwarze U, Byers PH, Weis M, Fernandes RJ, Eyre DR, Yao Z, Boyce BF, Lee B (2006) CRTAP is required for prolyl 3-hydroxylation and mutations cause recessive osteogenesis imperfecta. Cell 127:291-304

3. Barnes AM, Chang W, Morello R, Cabral WA, Weis M, Eyre DR, Leikin S, Makareeva E, Kuznetsova N, Uveges TE, Ashok A, Flor AW, Mulvihill JJ, Wilson PL, Sundaram UT, Lee B, Marini JC (2006) Deficiency of cartilage-associated protein in recessive lethal osteogenesis imperfecta. N Engl J Med 355: 2757-2764

4. Rauch F, Glorieux FH (2004) Osteogenesis imperfecta. Lancet 363:1377-1385

5. D'Amour P, Labelle F, Lecavalier L, Plourde V, Harvey D (1986) Influence of serum $\mathrm{Ca}$ concentration on circulating molecular forms of PTH in three species. Am J Physiol 251:E680-E687

6. Bollen AM, Eyre DR (1994) Bone resorption rates in children monitored by the urinary assay of collagen type I cross-linked peptides. Bone 15:31-34

7. Land C, Rauch F, Munns CF, Sahebjam S, Glorieux FH (2006) Vertebral morphometry in children and adolescents with osteogenesis imperfecta: effect of intravenous pamidronate treatment. Bone 39:901-906

8. Eastell R, Cedel SL, Wahner HW, Riggs BL, Melton LJ 3rd (1991) Classification of vertebral fractures. J Bone Miner Res 6: 207-215

9. Salle BL, Braillon P, Glorieux FH, Brunet J, Cavero E, Meunier PJ (1992) Lumbar bone mineral content measured by dual energy $\mathrm{X}$-ray absorptiometry in newborns and infants. Acta Paediatr 81:953-958

10. Ogden CL, Kuczmarski RJ, Flegal KM, Mei Z, Guo S, Wei R, Grummer-Strawn LM, Curtin LR, Roche AF, Johnson CL (2002) Centers for Disease Control and Prevention 2000 growth charts for the United States: improvements to the 1977 National Center for Health Statistics version. Pediatrics 109:45-60

11. Rauch F, Neu CM, Wassmer G, Beck B, Rieger-Wettengl G, Rietschel E, Manz F, Schoenau E (2002) Muscle analysis by measurement of maximal isometric grip force: new reference data and clinical applications in pediatrics. Pediatr Res 51: 505-510

12. Bleck EE (1981) Nonoperative treatment of osteogenesis imperfecta: orthotic and mobility management. Clin Orthop Relat Res 159:111-122

13. Haley SM, Coster WJ, Ludlow LH, Haltiwanger JT, Anrellos PJ (1992) Pediatric Evaluation of Disability Inventory (PEDI): development, standardization and administrative manual, New England Medical Center, Boston

14. Glorieux FH, Travers R, Taylor A, Bowen JR, Rauch F, Norman M, Parfitt AM (2000) Normative data for iliac bone histomorphometry in growing children. Bone 26:103-109

15. Parfitt AM, Drezner MK, Glorieux FH, Kanis JA, Malluche H, Meunier PJ, Ott SM, Recker RR (1987) Bone histomorphometry: standardization of nomenclature, symbols, and units. Report of the ASBMR Histomorphometry Nomenclature Committee. J Bone Miner Res 2:595-610

16. FH, Bishop NJ, Plotkin H, Chabot G, Lanoue G, Travers R (1998) Cyclic administration of pamidronate in children with severe osteogenesis imperfecta. N Engl J Med 339:947-952

17. Rauch F, Plotkin H, Travers R, Zeitlin L, Glorieux FH (2003) Osteogenesis imperfecta types I, III, and IV: effect of pamidronate therapy on bone and mineral metabolism. J Clin Endocrinol Metab 88:986-992 
18. Land C, Rauch F, Travers R, Glorieux FH (2007) Osteogenesis imperfecta type VI in childhood and adolescence: effects of cyclical intravenous pamidronate treatment. Bone 40:638-644

19. Zeitlin L, Rauch F, Travers R, Munns C, Glorieux FH (2006) The effect of cyclical intravenous pamidronate in children and adolescents with osteogenesis imperfecta type V. Bone 38:13-20
20. Rauch F, Travers R, Plotkin H, Glorieux FH (2002) The effects of intravenous pamidronate on the bone tissue of children and adolescents with osteogenesis imperfecta. J Clin Invest 110: 1293-1299 